\title{
Understanding the Factors That Are Associated with Motorcycle Crash Severity in Rural and Urban Areas of Ghana
}

\author{
William Agyemang, ${ }^{1}$ Emmanuel Kofi Adanu $\mathbb{D}^{2},{ }^{2}$ and Steven Jones ${ }^{3}$ \\ ${ }^{1}$ Building and Road Research Institute (BRRI), Fumesua, Ghana \\ ${ }^{2}$ Alabama Transportation Institute, The University of Alabama, Tuscaloosa, AL 35487, USA \\ ${ }^{3}$ Department of Civil, Construction and Environmental Engineering, The University of Alabama, Tuscaloosa, AL 35487, USA
}

Correspondence should be addressed to Emmanuel Kofi Adanu; ekadanu@crimson.ua.edu

Received 19 June 2021; Revised 1 November 2021; Accepted 25 November 2021; Published 22 December 2021

Academic Editor: Francesco Galante

Copyright (C) 2021 William Agyemang et al. This is an open access article distributed under the Creative Commons Attribution License, which permits unrestricted use, distribution, and reproduction in any medium, provided the original work is properly cited.

\begin{abstract}
Like many countries in sub-Saharan Africa, Ghana has witnessed an increase in the use of motorcycles for both commercial transport and private transport of people and goods. The rapid rise in commercial motorcycle activities has been attributed to the problem of urban traffic congestion and the general lack of reliable and affordable public transport in rural areas. This study investigates and compares factors that are associated with motorcycle crash injury outcomes in rural and urban areas of Ghana. This comparison is particularly important because the commercial use of motorcycles and their rapid growth in urban areas are a new phenomenon, in contrast to rural areas where people have long relied on motorcycles for their transportation needs. Preliminary analysis of the crash data revealed that more of the rural area crashes occurred under dark and unlit roadway conditions, while urban areas recorded more intersection-related crashes. Additionally, it was found that more pedestrian collisions happened in urban areas, while head-on collisions happened more in rural areas. The model estimation results show that collisions with a pedestrian, run-off-road, and collisions that occur under dark and unlit roadway conditions were more likely to result in fatal injury. Findings from this study are expected to help in crafting and targeting appropriate countermeasures to effectively reduce the occurrence and severity of motorcycle crashes throughout the country and, indeed, sub-Saharan Africa.
\end{abstract}

\section{Introduction}

Globally, road crashes are a leading cause of deaths and injuries, the burden of which is disproportionately borne by low- and middle-income countries, which account for more than $90 \%$ of the global road traffic fatalities. Motorcyclists, along with pedestrians and bicyclists, are among the vulnerable road users (VRUs) that represent more than $50 \%$ of road fatalities in sub-Saharan Africa [1]. This is alarming because motorcycles provide relatively high levels of mobility and accessibility at costs that are typically much lower than other modes such as private automobiles, taxis, minibuses, and other forms of public transport. As such, there has been a proliferation of motorcycle transport in much of the developing world, especially throughout subSaharan Africa $[2,3]$. Despite the harm caused by motorcycle deaths and injuries, they remain (and will likely continue to be) an important source of mobility and employment throughout the African continent [4]. As motorcycles and their usage continue to increase across the continent, there is an urgent need to identify and understand the factors that contribute to the occurrence and severity of motorcycle crashes to implement appropriate policies and countermeasures.

Like many countries in sub-Saharan Africa, Ghana has witnessed an increase in the use of motorcycles for both commercial transport and private transport of people and goods. The rapid rise in commercial motorcycle activities has been attributed to the problem of urban traffic congestion and the general lack of reliable and affordable public transport in rural areas. In most urban areas of the country, motorcycles have become the preferred alternative transport mode to the popular informal public transport minibuses (locally referred to as "tro-tros"). Commercial motorcycles 
have also become popular due to shorter travel times attributable to their ability to maneuver through traffic and being able to pick up and drop off passengers much closer to their origins and destinations, respectively, thereby overcoming the first/last mile challenge of public transport modes. Also, motorcycles typically provide increased travel time reliability compared with tro-tros as travelers do not have to wait for drivers to pick up additional passengers to ensure that the tro-tros are full and therefore as profitable as possible. In rural areas of Ghana, commercial motorcycles are often the only affordable and accessible means of motorized transport. Additionally, they often transport goods (e.g., agricultural products) in addition to passengers and, in some instances, are used as ambulances. Thus, it is understood that motorcycles are an important transport mode throughout Ghana and that they serve different functions in rural and urban areas of the country. As such, they provide essential mobility for many travelers throughout the country [5]. Furthermore, the thriving trade of commercial motorcycles in Ghana has employed many youths [6]. In response to the necessity and popularity of commercial motorcycle transport, Ghana is working to amend national legislation (Legislative Instrument 2180) that currently prohibits the use of motorcycles for fare-paying passenger transport services [7].

The safety impact of commercial motorcycle activities in Ghana continues to complicate attempts to regulate, enforce, and encourage their use. Indeed, motorcycle crashes have been on a steady increase across Ghana for several years and have garnered attention not only from legislators but also from the local transport safety community. Numerous earlier studies on motorcycle safety concerns in the country focused on the use of helmets as a key to motorcycle safety [8-11], with findings revealing that factors such as age, gender, educational levels, and the presence of passengers (pillion riders) affected their usage. Other more recent studies have focused on identifying the relationship among various crash risk factors (weather, road geometry, etc.) and injury severity outcomes of motorcycle crashes [12, 13]. In addition to the obvious negative health impacts of motorcycle crashes in Ghana, they also have a negative economic impact. For example, Ref. [14] estimated the economic burden of motorcycle crashes in the Bolgatanga Municipality in Northern Ghana to be upwards of one million dollars as crash victims were largely found to be males in what would have otherwise been their most economically productive years.

Recognizing the previous works and the ongoing complex nature of motorcycle use and safety concerns, this study analyzed motorcycle crashes in Ghana with a specific focus on understanding the differences in injury severity between those that occurred in urban and rural settings. The rationale for this comparison stems from the fact that the commercial use of motorcycles and their rapid growth in urban areas of the country are a new phenomenon, in contrast to rural areas where people have relied on motorcycles for many years. Additionally, traffic and roadway conditions are significantly different between urban and rural areas. Therefore, the segmentation of motorcycle crashes based on the crash location would allow for a detailed understanding of the differences and similarities in the contributing factors of crash outcomes. We applied a mixed logit modeling technique to attempt to capture unobserved heterogeneity in the crash data to better inform future efforts towards crafting and targeting appropriate countermeasures to effectively reduce the occurrence and severity of motorcycle crashes in Ghana and, hopefully by extension, elsewhere in sub-Saharan Africa.

\section{Literature Review}

There have been myriad studies on the contributing factors and outcomes of motorcycle crashes throughout the world. Reported contributing factors observed range from human factors such as gender, age, and rider condition at the time of the crash [6, 15-24]; roadway geometric characteristics such as road width, horizontal and vertical curves, number of lanes, and shoulder width [25-27]; and environmental factors such as weather, roadway surface condition, crash scene lighting condition, and location of a crash [28, 29]; and vehicle factors $[25,29,30]$. Different road user behaviors increase the risk of motorcycle crashes. Ref. [31] assessed motorist right-of-way (ROW) violations at $\mathrm{T}$ junctions and their safety concerns for motorcyclists. Findings from the study revealed that motorcyclists' ROW was likely to be violated in non-built-up areas, under poor lighting conditions, and by older females. Multiple factors have been found to be linked to various injury outcomes of motorcycle crashes. For instance, Ref. [20] found that rear-end collision, speeds greater than or equal to $55 \mathrm{mph}$, location of the crash, lighting condition, rider gender, road surface condition, and helmet use affect the outcomes of crashes involving motorcycles. Ref. [26] investigated how roadway characteristics, environmental factors, traffic factors, maneuver types, and driver behavior influence right-angle crashes involving motorcycles at intersections. In particular, the study found that nighttime riding, driving on the curb and median, and driver running red light affect the severity of motorcycle crashes.

Ref. [32] identified factors that affect the severity of motorcycle injuries among young adult riders in rural and urban areas in Taiwan. The proportional odds model was used for the study, and it was found that rural roads, collision with heavier objects, make of motorcycle, dark lighting condition, and greater speed might increase the injury severity of motorcycle riders among young adults. Furthermore, the adjusted odds ratio (OR) revealed that rural roads were more likely to record higher severity of injuries compared with urban roads. Ref. [33] assessed motorcyclerelated crashes and injury risk in rural and urban areas in Australia. The study found that injury crashes in rural regions occurred at higher proportions than expected in urban regions. Thirty-five percent of injury crashes (and $40 \%$ of fatal and serious injury crashes) were in rural regions and just under 30\% (and just over 30\% of fatal and serious injury crashes) occurred in speed zones of $80 \mathrm{~km} / \mathrm{hr}$ or more. Research conducted to compare factors affecting motorcycle crash outcomes in a rural versus urban context revealed that 
variables such as clear weather and roadway without light were found to be significant predictors in the rural model, whereas variables such as older female motorcyclists and horizontal curve were found significant in the urban model, and alcohol influence, non-usage of a helmet, and high speed were significant in both models [28].

Ref. [27] also observed that impaired riding, rider gender, lighting, and roadway geometry affect crash severity. The study further revealed that between 2000 and 2017, a significant proportion of motorcycle crash studies were on crash prevention of strategies. Ref. [18] identified the risk factors associated with motorcycle crashes and specifically found that younger riders under 19 years were most at risk and half of the fatal motorcycle crashes in Norway involved sports motorbikes. Ref. [18, 19] observed that $62 \%$ of children who were involved in fatal and serious injury motorcycle crashes were aged between 10 and 16 years. The study further found that most of the crashes happened on rural roads with speeds between 50 and $70 \mathrm{~km} / \mathrm{h}$ and over $50 \%$ of the children who sustained head injuries did not use a helmet. Ref. [34] found that at $70 \mathrm{~km} / \mathrm{h}$, the risk of motorcyclists sustaining a serious injury in a collision with wide objects, crash barriers, and narrow objects is $20 \%, 51 \%$, and $64 \%$, respectively, whereas the risk of a head-on collision between a motorcycle and a passenger car at $60 \mathrm{~km} / \mathrm{h}$ was estimated to be 55\%. Ref. [32] explored the relationship between the geometric characteristics and traffic flow characteristics of non-signalized intersections and the incidence of motorcycle crashes, while Ref. [29] found riders with no formal education to have higher chances of getting into serious injury crashes.

Ref. [35] observed that pillion riders were more at risk of sustaining injuries compared with motorcycle riders as the pillion riders were less likely to use crash helmets, and Ref. [10] found that gender, age, marital status, and license status affect helmet use. Ref. [36] investigated motorcycle-related road traffic crashes in Kigali, Rwanda. The results revealed that $80 \%$ of the victims were male, with most of the injuries occurring at the lower extremities (33\%), head (30\%), and upper extremities (16\%). Ref. [37] investigated the incidence and trend of motorcycle injuries. The study revealed that riders were the most killed (84\%), followed by pedestrians $(16 \%)$, and the rate of helmet use was very low $(0.3 \%)$. Ref. [38] explored the risk perception of commercial motorcyclists in Ibadan, Nigeria, where they found that there was a need for regulations for training and licensing of motorcyclists and stringent measures to enforce road traffic rules.

Ref. [39] investigated the crash characteristics and socioeconomic impact of low-volume roads in Tanzania. The results indicated that the majority $(71 \%)$ of injury crashes involved a motorcycle. Some $71 \%$ of those involved in motorcycle crashes were male, and more than $80 \%$ of those were 27 years of age on average. Ref. [40] examined the growth of motorcycles and the functioning of the motorcycle taxi industry in Lomé, Togo. The results showed that the heterogeneous characteristics of the players in the industry and strong linkages with formal activities have contributed to its sustainability. Ref. [41] observed the benefits and challenges of usage of motorcycles in rural areas of sub-
Saharan Africa. The findings from this study show that regulatory frameworks and enforcement of safety need to be improved. Furthermore, the formation of motorcycle associations is paramount for improved safety. Ref. [42] assessed the use of free reflective fluorescent motorcycle vest to improve the safety of motorcyclists. The results revealed an increase of $6.2 \%$ use rate, which indicates the importance of removing the economic barriers in support of safety improvement. Ref. [43] examined the operations of the motorcycle taxi in Lomé, Togo. The results reinforced the need to identify measures to formalize the operations of the motorcycle business and improve its safety concerns as an alternative, since banning motorcycles would have a negative consequence on livelihoods, especially in the rural areas.

\section{Methodology}

Many motorcycle crash studies have previously been carried out to understand the factors that influence motorcyclist behaviors and how crash factors are associated with injury severity outcomes. For instance, Ref. [35] used odds ratio and chi-square tests to assess the relative vulnerability of motorcyclists and passenger injury severity, while Ref. [8] used cross-sectional observations and chi-square tests to investigate the prevalence of helmet use among motorcycle riders and pillion riders in Ghana. Due to the classification of crash severity into discrete outcomes, discrete outcome models, ordered (probit and logit models) and unordered (such as the multinomial logit model) models, have been used to analyze crash severity (see [15, 17, 27, 28, 44-46] for injury severity methodology reviews). For instance, Ref. [46] developed various forms of mixed multinomial logit models to investigate factors associated with injury outcomes for interstate crashes. Previous motorcycle injury severity studies have also used mixed multinomial logit [20,26, 31], mixed multinomial logit with heterogeneity in means and variances [29], logistic regression [10, 11, 18, 22, 24, 34], and generalized ordered logit models $[12,25]$. Some recent studies have adopted machine-learning techniques to explore motorcycle-involved crashes and injury severity [47-51]. Indeed, the choice of method for studying motorcycle crashes depends on multiple factors, including but not limited to the scope of the study, study objectives, data quality, and preference. In fact, safety researchers are divided based on the choice of statistical methods or machinelearning techniques. For instance, while Ref. [52] argues that parametric models outperform data machine-learning approaches in the explanation of the associations between crash severity and the interrelated variables, other researchers $[53,54]$ observed that machine-learning techniques have the capability to explain the complex nonlinear relationships among crash variables.

Unobserved heterogeneity in crash data is an important concern in traffic safety research [55]. Choosing an appropriate model that accounts for unobserved heterogeneity can achieve a better fit of the data and improve model estimates, and ultimately the inferences that are made from the model estimates. To account for the effects of unobserved heterogeneity, this study used mixed multinomial logit 
modeling techniques. The details of the mixed multinomial logit model formulation are summarized in Table 1.

The mixed multinomial logit model, a generalization of the traditional multinomial logit model, allows the parameter vector $\beta_{i}$ to vary across observations. This model form allows for the heterogeneity within the observed crash data by varying the elements of $\beta_{i}$. The outcome-specific constants and elements of $\beta_{i}$ may either be fixed or be randomly distributed overall parameters with fixed means. The mixed multinomial logit model is obtained by introducing random parameters with $f\left(\beta_{i} \mid \varphi\right)$, as the mixing function where $\varphi$ is a vector of parameters of the chosen density function (mean and variance). A variable is random if it produces a statistically significant standard deviation, else the variable is restricted to be fixed.

Estimating the maximum likelihood of mixed multinomial logit models is computationally complex; hence, simulation-based methods are used. Such methods are typically based on the Halton sequence (or the Halton draws), to generate a systematic nonrandom sequence of numbers. Studies have shown that the Halton draws are more efficient and achieve more accurate probability approximations with fewer draws than purely random draws $[59,60]$. For this study, 500 Halton draws were used to estimate the mixing distributions for this study. To gain a better understanding of the relationship between crash factors and crash outcomes, marginal effects were computed to investigate the effect of individual parameters on the probability of the injury severity outcomes [57].

\section{Data and Empirical Setting}

Motorcycle crash data used for this study were obtained from the Ghana National Road Traffic Accident Database at the Building and Road Research Institute (BRRI) of the Council for Scientific and Industrial Research (CSIR). The data were retrieved from the Motor Traffic and Transport Department (MTTD) of the Ghana Police Service. The database at BRRI has served as the primary source of crash data for research and policy decision-making in Ghana since 1991. Five years of motorcycle crash records, covering the period from 2014 to 2018, were used for this study. The database was queried to select crash factors such as rider demographic characteristics, environmental condition, weather condition, time of the crash, roadway geometry, and vehicle characteristics. For analysis and modeling purposes, the data were further divided into urban and rural areas. Four injury severity levels (fatal injury, incapacitating injury, minor injury, and no injury) were used as classification criteria for the crash outcomes. Figure 1 shows a comparison of the distribution of motorcycle crash injury severity between rural and urban areas over the study period, and Table 2 presents the descriptive statistics of the variables that were used in the model estimations.

Figure 1 revealed that rural areas recorded more $(21 \%$ points) fatal motorcycle crashes than urban areas. The proportion of incapacitating injury crashes was similar for both rural and urban areas, but urban areas recorded more minor injuries and no injury crashes.
Preliminary data analysis (Table 2) shows that $28.2 \%$ of all motorcycle crashes in rural areas are head-on collisions, whereas in urban areas, head-on collisions make up $15.1 \%$ of the crash observations. In addition, $8.5 \%$ of rural area crashes were run-off-road compared with $4.3 \%$ of urban areas, while urban areas recorded more rear-end collisions (25.5\% compared with $20.5 \%$ of rural areas) and collisions at 4 -way stops ( $7.2 \%$ compared with $0.8 \%$ of rural areas). It was also observed that more pedestrian collisions happened in urban areas. Only $0.5 \%$ of rural area crashes occurred at signalized intersections compared with $11.6 \%$ of urban area crashes. Nearly $70 \%$ of rural area crashes happened under dark and unlit roadway conditions compared with $30.7 \%$ of urban areas.

\section{Results}

Separate mixed multinomial logit injury severity models were estimated for rural and urban motorcycle crashes in Ghana. Like previous crash injury severity studies $[28,46,61]$, during model estimation, variables were included in the specification if they had t-statistics corresponding to the $90 \%$ confidence interval on a two-tailed $t$ test. The random parameters, however, were included if their standard deviations had t-statistics corresponding to the $90 \%$ confidence interval. Likelihood-ratio tests were conducted to justify the development of separate models for rural and urban motorcycle crashes [57].

Tables 3 and 4 show that the rural and urban mixed multinomial logit models had McFadden pseudo- $\rho^{2}$ values of 0.2348 and 0.1494 , respectively. A wide variety of crash factors were found to be associated with the motorcycle crash injury severity outcomes. Variables with t-statistic greater than 2.58 indicate statistical significance at $99 \%$, while t-statistic values between 1.96 and 2.58 indicate statistical significance of $95 \%$, and t-statistic values greater than 1.65 but less than 1.96 indicate statistical significance of $90 \%$. In the urban area crash model, 22 factors were found to be significantly associated with the injury severity outcomes of motorcycle crashes, whereas 21 factors were found to influence the injury severity outcomes in rural areas. The injury outcome for which a variable was defined during model estimation is placed in a bracket as fatal injury [FI], incapacitating injury [II], minor injury [MI], and no injury [NI]. The effects of the variables on injury severity probabilities were found to vary as measured by the magnitude of their marginal effects. Detailed model estimation results for rural and urban motorcycle crashes are presented in Tables 3 and 4, respectively. Average marginal effects based on the population of observations are also presented in Tables 3 and 4. Marginal effects describe the effect of a unit change in the independent variable on the injury severity outcome probability. In the case of indicator variables, marginal effect gives the effect of the independent variables moving from zero to one on the injury severity outcome probabilities [57].

Two random parameters were found to be statistically significant in the rural model and only one was found to be significant in the urban model, indicating their varying influences on the injury severities. The normal distribution 
TABLE 1: Equations used in the mixed multinomial logit model formulation.

$\begin{array}{ll}\text { Equation Description } & \text { D }\end{array}$

$S_{i n}=$ severity function for category $i$ in crash $n, \beta_{i}=$ estimable severity parameters for category $i, X_{i n}=$ explanatory variables of severity category $i$ in crash $n, \varepsilon_{\text {in }}=$ error term-generalized extreme value distributed [56]

$S_{\text {in }}=\beta_{i} X_{\text {in }}+\varepsilon_{\text {in }}$ $P_{n}(i)=$ probability of $i$ th outcome occurring in the $n$th observation [57]

$P_{n}(i)=\exp \left(\beta_{i} X_{\text {in }}\right) / \Sigma \exp \left(\beta_{i} X_{\text {in }}\right)$

$P_{n}(i \mid \varphi)=\int \exp \left(\beta_{i} X_{\text {in }}\right) / \Sigma \exp \left(\beta_{i} X_{\text {in }}\right) f\left(\beta_{i} \mid \varphi\right) \beta_{i} \quad P_{n}(i \mid \varphi)=$ probability of injury severity $i$ conditional on $f\left(\beta_{i} \mid \varphi\right), \varphi=$ vector of parameters with known density function [58]

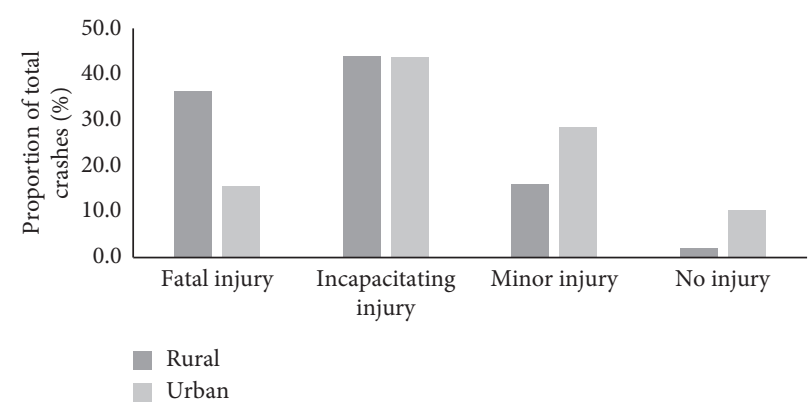

FIGURE 1: Distribution of motorcycle crash severity.

TABle 2: Descriptive statistics of variables used in model estimation.

\begin{tabular}{|c|c|c|c|c|}
\hline \multirow{2}{*}{ Variable } & \multicolumn{2}{|c|}{ Rural } & \multicolumn{2}{|c|}{ Urban } \\
\hline & Frequency & Proportion & Frequency & Proportion \\
\hline Roadway and environmental characteristics & 3,429 & 81.5 & 6,266 & 94.7 \\
\hline Straight and flat road & 3,429 & 81.5 & 6,266 & 94.7 \\
\hline Collision at 4 -way stop & 34 & 0.8 & 476 & 7.2 \\
\hline Collision at $\mathrm{T}$ junction & 362 & 8.6 & 1,085 & 16.4 \\
\hline Gravel road & 290 & 6.9 & 172 & 2.6 \\
\hline Paved roadway & 2,503 & 59.5 & 4,208 & 63.6 \\
\hline Collision at signalized intersection & 21 & 0.5 & 768 & 11.6 \\
\hline Wet pavement & 29 & 0.7 & 40 & 0.6 \\
\hline Light rain condition & 59 & 1.4 & 46 & 0.7 \\
\hline Poor visibility & 13 & 0.3 & 13 & 0.2 \\
\hline Dark and unlit lighting condition & 2,941 & 69.9 & 2,031 & 30.7 \\
\hline \multicolumn{5}{|l|}{ Motorcyclist factors } \\
\hline Rider age more than 60 & 72 & 1.7 & 60 & 0.9 \\
\hline Rider age between 45 and 60 & 332 & 7.9 & 483 & 7.3 \\
\hline Male rider & 4,173 & 99.2 & 6,538 & 98.8 \\
\hline Rider age less than 21 & 635 & 15.1 & 834 & 12.6 \\
\hline Rider not at fault & 1,027 & 24.4 & 1,667 & 25.2 \\
\hline \multicolumn{5}{|l|}{ Motorcycle factors } \\
\hline Steering defect & 97 & 2.3 & 112 & 1.7 \\
\hline Multiple motorcycle defects & 29 & 0.7 & 53 & 0.8 \\
\hline Wet pavement & 29 & 0.7 & 40 & 0.6 \\
\hline \multicolumn{5}{|l|}{ Collision type } \\
\hline Light rain condition & 59 & 1.4 & 46 & 0.7 \\
\hline Poor visibility & 13 & 0.3 & 13 & 0.2 \\
\hline Dark and unlit lighting condition & 2,941 & 69.9 & 2,031 & 30.7 \\
\hline Head-on collision & 1,186 & 28.2 & 999 & 15.1 \\
\hline Rider loss control & 164 & 3.9 & 179 & 2.7 \\
\hline Sideswipe & 673 & 16.0 & 1,191 & 18.0 \\
\hline Run-off-road & 358 & 8.5 & 285 & 4.3 \\
\hline Collision with pedestrian & 652 & 15.5 & 1,436 & 21.7 \\
\hline Multi-vehicle collision & 3,105 & 73.8 & 4,837 & 73.1 \\
\hline Rear-end crash & 862 & 20.5 & 1687 & 25.5 \\
\hline
\end{tabular}


TABLE 3: Mixed multinomial logit model estimation results for rural motorcycle crashes.

\begin{tabular}{|c|c|c|c|c|c|c|}
\hline \multirow[b]{2}{*}{ Variable } & \multirow[b]{2}{*}{$\begin{array}{l}\text { Parameter } \\
\text { estimate }\end{array}$} & \multirow[b]{2}{*}{$\begin{array}{c}\mathrm{t}- \\
\text { Statistic }\end{array}$} & \multicolumn{4}{|c|}{ Marginal effects } \\
\hline & & & $\begin{array}{l}\text { Fatal } \\
\text { injury }\end{array}$ & $\begin{array}{l}\text { Incapacitating } \\
\text { injury }\end{array}$ & $\begin{array}{l}\text { Minor } \\
\text { injury }\end{array}$ & $\begin{array}{l}\text { No } \\
\text { injury }\end{array}$ \\
\hline Constant $[\mathrm{FI}]$ & 2.732 & 15.93 & & & & \\
\hline Steering defect $[\mathrm{FI}]$ & 0.563 & 2.11 & 0.0023 & -0.0015 & -0.0007 & -0.0001 \\
\hline Straight and flat road [FI] & -0.320 & -3.01 & -0.0442 & 0.0225 & 0.0191 & 0.0026 \\
\hline Rider age more than $60[\mathrm{FI}]$ & 0.975 & 3.04 & 0.0028 & -0.0016 & -0.001 & -0.0002 \\
\hline Rider age between 45 and $60[\mathrm{FI}]$ & 0.471 & 3.11 & 0.0064 & -0.0036 & -0.0024 & -0.0004 \\
\hline Head-on collision $[\mathrm{FI}]$ & 1.273 & 10.89 & 0.0572 & -0.0321 & -0.0223 & -0.0029 \\
\hline Rider loss control [FI] & 0.460 & 2.37 & 0.0035 & -0.0022 & -0.0011 & -0.0002 \\
\hline Sideswipe $[\mathrm{FI}]$ & -0.575 & -4.60 & -0.0129 & 0.0048 & 0.0071 & 0.001 \\
\hline Constant [II] & 1.613 & 2.15 & & & & \\
\hline Multi-vehicle collision [II] & 0.257 & 2.07 & -0.0315 & 0.0419 & -0.0091 & -0.0013 \\
\hline $\begin{array}{l}\text { Standard deviation for "multi-vehicle collision" } \\
\text { (normally distributed) }\end{array}$ & 2.837 & 4.49 & & & & \\
\hline Dark and unlit lighting condition [II] & -0.321 & -2.65 & 0.0065 & -0.109 & 0.0038 & 0.0006 \\
\hline $\begin{array}{l}\text { Standard deviation for "dark and unlit roadway" } \\
\text { (normally distributed) }\end{array}$ & 1.092 & 1.86 & & & & \\
\hline Male rider $[\mathrm{II}]$ & 1.249 & 1.70 & -0.1088 & 0.1674 & -0.0522 & -0.0064 \\
\hline Collision at 4 -way stop [II] & 1.201 & 1.69 & -0.0007 & 0.0011 & -0.0004 & -0.0001 \\
\hline Collision at $\mathrm{T}$ junction $[\mathrm{MI}]$ & 0.227 & 1.74 & -0.0016 & -0.0009 & 0.0026 & -0.0001 \\
\hline Constant $[\mathrm{MI}]$ & 2.135 & 13.76 & & & & \\
\hline Paved roadway $[\mathrm{MI}]$ & -0.432 & -4.63 & 0.0175 & 0.0097 & -0.0286 & 0.0014 \\
\hline Rider not at fault $[\mathrm{MI}]$ & 0.339 & 3.11 & -0.0067 & -0.0034 & 0.0107 & -0.0006 \\
\hline Rider age less than 21 [MI] & 0.320 & 2.65 & -0.0039 & -0.0026 & 0.0068 & -0.0003 \\
\hline Run-off-road [MI] & -0.667 & -3.65 & 0.003 & 0.0023 & -0.0055 & 0.0002 \\
\hline Collision with pedestrian [NI] & -2.939 & -2.91 & 0.0003 & 0.0003 & 0.0002 & -0.0007 \\
\hline Wet pavement $[\mathrm{NI}]$ & 1.729 & 2.64 & -0.0005 & -0.0003 & -0.0002 & 0.001 \\
\hline Rear-end crash $[\mathrm{NI}]$ & 0.431 & 1.88 & -0.0015 & -0.0007 & -0.0009 & 0.0031 \\
\hline Model statistics & & & & & & \\
\hline Number of observations & 4207 & & & & & \\
\hline Log-likelihood restricted & -5832.14 & & & & & \\
\hline Log-likelihood at convergence & -4462.51 & & & & & \\
\hline McFadden pseudo- $\rho^{2}$ & 0.23 & & & & & \\
\hline
\end{tabular}

provided the best statistical fit for these random parameters. The effects of the rest of the crash factors were fixed. The two random parameters found to be statistically significant in the rural model are the indicator variables for multi-vehicle collision and roadway lighting conditions being dark and unlit. The dark and unlit roadway indicator variable was also found to have a statistically significant random parameter in the urban model.

The rural multi-vehicle collision variable defined for incapacitated injury was found to be a random parameter with a mean of 0.257 and standard deviation of 2.837 and assumed to be normally distributed. This indicates that for $53.6 \%$ of the multi-vehicle collision crash data, the probability of incapacitated injury is high, whereas in the remaining $46.4 \%$ of the crash data the likelihood of incapacitated injury is low. This shows that the likelihood of incapacitated injury for motorcycle crashes in rural settings is high. The dark and unlit roadway indicator variable (defined for incapacitated injury) for the rural area had a mean of -0.321 and a standard deviation of 1.092. This implies that for $38.4 \%$ of rural crashes that occurred on dark and unlit roadways, the probability of an incapacitated injury is low, while the chance of incapacitated injury is high for the remaining $61.8 \%$ of motorcycle crashes. This further shows that there is a high chance of incapacitating injury in rural area motorcycle crashes under dark roadway conditions. Similarly, the interpretation of the mean and standard deviation values for the dark and unlit roadway indicator variable for urban motorcycle crashes, defined for incapacitating injury, revealed a decrease in the probability of incapacitated injury in $48.9 \%$ of the crashes, while variable increases the likelihood of incapacitated injury in the remaining $51.1 \%$ of the crashes. For the remaining fixed variables, those with similar attributes are grouped together, compared between the two models, and discussed accordingly.

5.1. Collision Types. The difference in size and mass between motorcycles and vehicles influences the severity outcome of motorcycle-involved multi-vehicle crashes. In this study, it was observed that the probability of fatal injury for motorcycle crashes involving sideswipe and rear-end collisions in rural settings is lowered by 0.0129 and 0.0015 , respectively. However, there is a high probability that sideswipe crashes could lead to other injuries severities in both rural and urban areas. 
TABle 4: Mixed multinomial logit model estimation results for urban motorcycle crashes.

\begin{tabular}{|c|c|c|c|c|c|c|}
\hline \multirow[b]{2}{*}{ Variable } & \multirow[b]{2}{*}{$\begin{array}{l}\text { Parameter } \\
\text { estimate }\end{array}$} & \multirow[b]{2}{*}{$\begin{array}{c}\mathrm{t}- \\
\text { statistic }\end{array}$} & \multicolumn{4}{|c|}{ Marginal effects } \\
\hline & & & $\begin{array}{l}\text { Fatal } \\
\text { injury }\end{array}$ & $\begin{array}{l}\text { Incapacitating } \\
\text { injury }\end{array}$ & $\begin{array}{l}\text { Minor } \\
\text { injury }\end{array}$ & $\begin{array}{l}\text { No } \\
\text { injury }\end{array}$ \\
\hline Constant [FI] & 1.448 & 2.67 & & & & \\
\hline Straight and flat road [FI] & -0.441 & -3.14 & -0.0488 & 0.0214 & 0.0205 & 0.0069 \\
\hline Rider age more than $60[\mathrm{FI}]$ & 0.915 & 2.98 & 0.0015 & -0.0007 & -0.0006 & -0.0002 \\
\hline Rider age between 45 and 60 [FI] & 0.513 & 4.08 & 0.0056 & -0.0024 & -0.0023 & -0.0009 \\
\hline Light rain condition $[\mathrm{FI}]$ & 1.055 & 2.62 & 0.0011 & -0.0003 & -0.0005 & -0.0002 \\
\hline Poor visibility $[\mathrm{FI}]$ & 1.648 & 2.70 & 0.0007 & -0.0003 & -0.0003 & -0.0001 \\
\hline Head-on collision [FI] & 1.441 & 15.18 & 0.0436 & -0.0184 & -0.0169 & -0.0083 \\
\hline Rider loss control [FI] & 0.402 & 1.98 & 0.0016 & -0.0007 & -0.0007 & -0.0002 \\
\hline Sideswipe $[\mathrm{FI}]$ & -0.544 & -4.25 & -0.0065 & 0.0027 & 0.0025 & 0.0012 \\
\hline Multi-vehicle collision [II] & -0.363 & -4.08 & -0.0297 & 0.0126 & 0.0116 & 0.0055 \\
\hline Constant $[\mathrm{II}]$ & 2.057 & 3.95 & & & & \\
\hline Dark and unlit lighting condition [II] & -0.125 & -0.53 & -0.0025 & 0.0062 & -0.0026 & -0.0012 \\
\hline $\begin{array}{l}\text { Standard deviation for "dark and unlit roadway" } \\
\text { (normally distributed) }\end{array}$ & 4.463 & 1.95 & & & & \\
\hline Gravel road $[\mathrm{IHI}]$ & 0.315 & 1.70 & -0.0005 & 0.0016 & -0.0008 & -0.0003 \\
\hline Constant $[\mathrm{MI}]$ & 1.778 & 3.40 & & & & \\
\hline Collision at $\mathrm{T}$ junction $[\mathrm{MI}]$ & 0.432 & 5.68 & -0.0035 & -0.0086 & 0.0152 & -0.0031 \\
\hline Paved roadway $[\mathrm{MI}]$ & -0.310 & -5.22 & 0.0094 & 0.0195 & -0.0355 & 0.0066 \\
\hline Collision at signalized intersection [MI] & 0.148 & 1.68 & -0.0008 & -0.002 & 0.0036 & -0.0007 \\
\hline Collision with pedestrian $[\mathrm{NI}]$ & -5.437 & -5.43 & 0.0002 & 0.0003 & 0.0003 & -0.0008 \\
\hline Male rider $[\mathrm{NI}]$ & 0.924 & 1.77 & -0.0155 & -0.0338 & -0.0313 & 0.0805 \\
\hline Steering defect $[\mathrm{NI}]$ & 0.866 & 3.54 & -0.0005 & -0.0009 & -0.0008 & 0.0022 \\
\hline Multiple motorcycle defects [NI] & 1.210 & 3.35 & -0.0003 & -0.0006 & -0.0006 & 0.0015 \\
\hline Model statistics & & & & & & \\
\hline Number of observations & 6617 & & & & & \\
\hline Log-likelihood restricted & -9173.11 & & & & & \\
\hline Log-likelihood at convergence & -7848.12 & & & & & \\
\hline McFadden pseudo- $\rho^{2}$ & 0.14 & & & & & \\
\hline
\end{tabular}

The results also show that the head-on collision indicator for rural areas increases the probability of fatal injury by 0.0572 compared with a slightly lower chance $(0.0436)$ of fatal injury in urban areas. It was further observed that the collision with pedestrian indicator variable reduces the likelihood of no injury by 0.0008 and 0.0007 in rural and urban settlements, respectively. This indicates that motorcycle crashes that involve a collision with a pedestrian have higher chances of resulting in some form of injury. Run-off-road motorcycle crashes in rural areas were more likely to lead to fatal injuries. The model estimation results further reveal that crashes in which the rider lost control had a higher likelihood of resulting in fatal injury in both rural and urban settings. In situations where another vehicle, other than a motorcycle, was deemed to be at fault in motorcycle-involved crashes, the chances of minor injury are increased by 0.0068 in rural areas.

5.2. Roadway and Environmental Characteristics. It has been observed that weather conditions (e.g., rainfall) affect the injury severity of motorcycle crashes [62]. In this study, it was observed that the rain indicator variable increases the likelihood of fatal injury by 0.0011 in urban areas, while the likelihood of other injury outcomes is lower. In rural areas, motorcycle crashes that happened on wet roadways were less likely to record any form of injury. This observation may be due to lower traffic volumes during rain or riders being cautious and not speeding. With respect to the roadway curvature and conditions, the straight and flat roadway variable was found to reduce the probability of fatal injury by 0.0442 and 0.0488 in rural and urban areas, respectively, while the likelihood of other injury outcomes is higher. This shows that the chances of fatal motorcycle crashes are high on roadways with some form of curvature and grade, in both rural and urban areas.

The results further suggest that, except for minor injury outcome, the paved road indicator variable increases the probability of the other injury outcomes in both rural and urban areas. In urban areas, motorcycle crashes that occurred on unpaved roads were more likely to record incapacitating injury. The dark and unlit roadway indicator variable increased the likelihood of fatal injury outcome in rural areas by 0.0065 , whereas the probability of fatal injury is lowered by 0.0025 in urban areas. However, motorcycle crashes that happened in urban areas under poor visibility conditions were more likely to result in fatalities. The indicator variable for collision at fourway intersection increased the chance of incapacitating injury by 0.0011 in rural areas, while the $\mathrm{T}$ junction variable increased the probability of minor injury by 0.0026 in the rural area motorcycle crash model and 0.0152 in the urban area model.

5.3. Vehicle Characteristics. As shown in Tables 3 and 4, only one and two vehicle-related variables were found to be significant in the rural and urban setting models, 
respectively. The results show that motorcycle crashes that occurred as a result of steering defects have an increased likelihood of recording fatal injury in rural areas, whereas in urban areas crashes that occurred due to steering defects were less likely to be fatal. Urban crashes that involve motorcycles with multiple defects were less likely to result in injury. This shows that fatal crashes due to steering defects are more pronounced in rural areas in Ghana.

5.4. Rider Characteristics. Motorcycle rider age was classified into four groups: younger than 21, between 21 and 40, between 40 and 60, and above 60 years of age. Three age group variables were found to be significant in the models. The model estimation results show that the indicator variable for riders aged between 45 and 60 years increased the probability of fatal injury by 0.0064 and 0.0056 in the rural and urban models, respectively. The study also found that the variable for riders aged above 60 years increased the probability of fatal injury by 0.0026 and 0.0015 in rural and urban areas, respectively. These findings are consistent with other studies [28]. However, younger riders (rider age less than 21) were less likely to be killed in rural settlements. The male gender variable was found to be significant in both models. This variable increased the probability of incapacitating injury by 0.1674 in rural areas and increased the likelihood of no injury by 0.0805 in urban settlements.

\section{Discussion}

Motorcycle crashes often lead to severe injury outcomes because by design motorcycles provide minimal physical protection to riders. This makes motorcyclists more vulnerable to injuries than other motor vehicle users when they get into crashes $[20,63]$. Indeed, the World Health Organization classifies motorcyclists as vulnerable road users [1]. The rapid increase in the use of motorcycles to meet daily mobility demands in low- and middle-income countries, in an informal and often unregulated manner, may be a barrier to achieving the Sustainable Development Goal (SDG) Target 3.6, which calls for a 50\% reduction in the number of road traffic fatalities by 2030 . The critical roles of commercial motorcycles in providing employment to youth and filling a basic mobility gap in many developing countries make banning or regulating their activities a political issue that governments find difficult to undertake, even though the increased activity of motorcyclists has significantly contributed to many traffic fatalities. This study contributes to efforts to identify areas for countermeasure implementation to reduce motorcycle crashes and injury severity in Ghana.

The model results presented in the previous section reveal some findings that can support efforts towards improving overall traffic safety in Ghana. It has been observed that motorcycle defects contribute significantly to fatal injury outcomes across the country. This finding calls for a comprehensive education on basic motorcycle maintenance practices for commercial motorcyclists as their motorcycles tend to be overused to meet daily sales targets, compared with recreational riders. It was also found that collision with pedestrians has also resulted in many fatalities across the country. It would be important for the National Road Safety Authority (NRSA) to advocate for the implementation of safer speed policies in mixed traffic zones, especially in urban areas where pedestrian collisions were observed to be high. Speed calming measures may be provided to reduce some of these crashes. While law enforcement and punitive measures may also be employed to achieve rider discipline on the road, enforcement can sometimes be compromised by bribery and corruption [64]. To address the challenge of corruption in traffic law enforcement, comprehensive education of motorists about their rights and responsibilities can ensure that they are not coerced to pay bribes to law enforcement officers to get away with minor traffic violations. Additionally, punitive measures would need to be stringent, but not too severe, so as not to make bribery appear to be a better option. Furthermore, technology may be introduced into traffic law enforcement to minimize motorist enforcement officer interactions. If traffic law enforcement is effectively and appropriately implemented, it will ensure compliance with helmet use laws by both riders and pillion riders.

Additionally, the findings from this study provide evidence for the adoption and implementation of the safe system approach to road safety improvement. For instance, the finding that run-off-road crashes were more likely to result in fatal injury in rural areas suggests that measures such as the creation of clear zones that allow drivers/motorcyclists to recover and reenter the roadway or installation of reflective guardrails to prevent riders, and indeed, drivers from running into ditches or colliding with trees and other fixed objects off the roadway, particularly at night in rural areas, could yield positive results. Warning signs may be installed at high-risk locations, such as intersections, to warn riders and drivers of upcoming transitions in roadway geometry and traffic bottlenecks ahead. Furthermore, roadway shoulders need to be properly maintained to help riders bring their motorcycles to a safe stop off the travel lanes when the need arises. The findings and recommendations from the study, therefore, provide a foundation for safe system approach [58] to improving motorcycle safety in Ghana. Table 5 provides recommendations of countermeasures that may be implemented within the framework of the safe systems to improve motorcycle safety in the country.

\section{Limitation}

The Ghana crash data do not contain alcohol-related and crash helmet use information, and hence, this information was not available for analysis in this study. While acknowledging this limitation, the authors assert that findings from previous studies on the effects of alcohol involvement and the nonuse of helmets on motorcycle crash severity are highly likely applicable even in the Ghanaian context. Additionally, the issue of underreporting of crashes in the country [65] means that a good number of crashes, especially low severity crashes, may not have been captured in the crash database. This means that the model estimation results relating to the lower severity outcomes could have been 
TABLE 5: Safe system approach for the rural and urban environment with respect to fatal injury.

\begin{tabular}{|c|c|c|}
\hline Variable & $\begin{array}{l}\text { Safe system } \\
\text { indicator }\end{array}$ & Countermeasures \\
\hline Steering defect (vehicle defects) & Safe vehicle & \\
\hline $\begin{array}{l}\text { Rider age (rider demographic } \\
\text { characteristics) }\end{array}$ & Safe people & \\
\hline Head-on collision & $\begin{array}{l}\text { Safe road } \\
\text { Safe speed } \\
\text { Safe vehicle } \\
\text { Safe road }\end{array}$ & $\begin{array}{c}\text { Safe vehicle: advance riding/driving assistance systems, regular basic maintenance } \\
\text { checks } \\
\text { Safe people: education and training for motorcyclists, legal framework to regulate } \\
\text { activities of motorcyclists, targeted law enforcement, road safety campaigns for }\end{array}$ \\
\hline Collision with pedestrian & $\begin{array}{l}\text { Postcrash care } \\
\text { Safe people }\end{array}$ & $\begin{array}{l}\text { pedestrians } \\
\text { Safe road: physical opposing lane separation increase roadway capacity creation of }\end{array}$ \\
\hline Rider loss control/run-off-road & $\begin{array}{l}\text { Safe road } \\
\text { Safe vehicle }\end{array}$ & $\begin{array}{l}\text { clear zones that allow drivers/motorcyclists to recover and reenter the roadway or } \\
\text { guardrails at embankments, road signs and markings, provision of lighting systems, }\end{array}$ \\
\hline $\begin{array}{l}\text { Paved roadway/roadway } \\
\text { geometry }\end{array}$ & $\begin{array}{l}\text { Safe road } \\
\text { Safe speed }\end{array}$ & $\begin{array}{l}\text { and roadway shoulder } \\
\text { Postcrash care: provision of first aid to accident victims by medical professionals and }\end{array}$ \\
\hline $\begin{array}{l}\text { Poor visibility/lighting } \\
\text { condition }\end{array}$ & $\begin{array}{l}\text { Safe road } \\
\text { Safe speed } \\
\text { Safe people }\end{array}$ & $\begin{array}{l}\text { Safe speed: installation of speed cameras, road signs, and markings, law enforcement, } \\
\text { an overspeed warning system for motorcyclists, speed calming measures }\end{array}$ \\
\hline $\begin{array}{l}\text { Rainy condition/road surface } \\
\text { condition }\end{array}$ & $\begin{array}{l}\text { Safe road } \\
\text { Safe speed } \\
\text { Safe people }\end{array}$ & \\
\hline
\end{tabular}

different. Despite this limitation, the findings of the study provide some relevant information to improve motorcycle safety concerns in the country.

\section{Conclusions}

The rising use of commercial motorcycles for daily trip making in many developing countries in a largely unregulated environment can be a barrier to achieving safe transport systems. As part of efforts to reduce motorcycleinvolved crashes, this research provides a disaggregated injury severity analysis of motorcycle crashes on rural and urban roadways in Ghana. Preliminary data analysis of the data revealed that more of the rural area crashes occurred under dark and unlit roadway conditions, while urban areas recorded more intersection-related crashes. Additionally, it was found that more pedestrian-motorcycle crashes happened in urban areas, while head-on collisions with other vehicles happened more often in rural areas. Separate mixed multinomial logit models for rural and urban motorcycle crashes were developed to identify various crash factors that influence motorcycle crash outcomes. The findings of the study are expected to lead to effective, and targeted policy decisions aimed at improving motorcycle safety, particularly in rural Ghana where motorcycle transport is playing a vital role in place of traditional public transport. The goal of doing away with it, especially in the rural areas, would have a negative effect on their livelihood.

Two parameters for the rural model and one parameter for the urban model were found to be random, indicating their varying associations with injury severity. The results of the study showed some similarities and differences between the factors that influence the injury severity of motorcycle crashes that occur in rural and urban areas in Ghana. For example, variables such as dark and unlit roadway and collision at $\mathrm{T}$ junctions were found significant in both the rural and urban models. Similarly, the run-off-road variable was found to be significant in both models. The model estimation results show that collisions with a pedestrian, run-off-road, collisions that occur under dark and unlit roadway conditions were more likely to result in fatal injury. It was also found that while steering defects contributed significantly to fatal injury in rural areas, crashes involving steering defects were less likely to record any injury in urban areas.

Ultimately, the findings of this study provide the basis for adopting safe system measures to improve motorcycle safety in Ghana, considering the importance of motorcycles in providing daily mobility for many people. While law enforcement strategies are recommended to reduce the occurrence of crashes, the finding on the role of motorcycle defects in fatal crashes calls for a comprehensive education on basic motorcycle maintenance practices for commercial motorcyclists.

\section{Data Availability}

The crash data used to support the findings of this study are available from the corresponding author upon request.

\section{Conflicts of Interest}

The authors declare that they have no conflicts of interest.

\section{References}

[1] World Health Organization (Who), Global Status Report on Road, World Health Organization, Geneva, Switzerland, 2018.

[2] A. Kumar, Understanding the Emerging Role of Motorcycles in African Cities: A Political Economy Perspective, Sub-Sahara Africa Transport Policy Program (SSATPP), The World Bank Group, Washington, DC, USA, 2011. 
[3] L. D. Olvera, D. Plat, P. Pochet, and S. Maïdadi, "Motorbike taxis in the "transport crisis" of West and Central African cities," EchoGéo, vol. 20, 2012.

[4] D. Ehebrecht, D. Heinrichs, and B. Lenz, "Motorcycle-taxis in sub-Saharan Africa: current knowledge, implications for the debate on "informal" transport and research needs," Journal of Transport Geography, vol. 69, pp. 242-256, 2018.

[5] M. O. Ababio and E. Agyemang, "The Okada War in Urban Ghana: a polemic issue or policy mismatch?" African Studies Quarterly, vol. 15, pp. 25-44, 2015.

[6] A. Zuure and D. N. Yiboe, "The phenomenon of commercial motorbike transportation and its impact on the youth of Agbozume traditional area in the Ketu south municipality in the Volta region of Ghana," International Journal of Development and Sustainability, vol. 6, pp. 1689-1700, 2017.

[7] F. Afukaar and J. Damsere-Derry, Facilitation Services for Consultation on Motorcycles Operations in Ghana, Building and Road Research Institute (Council for Scientific and Industrial Research), Ejisu, Ghana, 2019.

[8] W. Ackaah and F. K. Afukaar, "Prevalence of helmet use among motorcycle users in tamale metropolis, Ghana: an observational study," Traffic Injury Prevention, vol. 11, no. 5, pp. 522-525, 2010.

[9] W. Ackaah, F. Afukaar, W. Agyemang et al., "The use of nonstandard motorcycle helmets in low- and middle-income countries: a multicentre study," Injury Prevention, vol. 19, pp. 158-163, 2013.

[10] M. A. Akaateba, I. Yakubu, and B. A. A. Akanbang, "Correlates and barriers associated with motorcycle helmet use in wa, Ghana," Traffic Injury Prevention, vol. 16, no. 8, pp. 809-817, 2015.

[11] E. N. Aidoo, S. Bawa, and C. A. Yirenkyi, "Prevalence rate of helmet use among motorcycle riders in Kumasi, Ghana," Traffic Injury Prevention, vol. 19, no. 8, pp. 856-859, 2018.

[12] E. N. Aidoo and R. A. Gyimah, "Modelling the risk factors for injury severity in motorcycle users in Ghana," Journal of Public Health, vol. 28, no. 2, pp. 199-209, 2019.

[13] F. Dapilah, B. Y. Guba, and E. O. Sekyere, "Motorcyclist characteristics and traffic behaviour in urban Northern Ghana: implications for road traffic accidents," Journal of Transport \& Health, vol. 4, pp. 237-245, 2017.

[14] M. Kudebong, F. Wurapa, J. Nonvignon, I. Norman, J. K. A. Williams, and M. Aikins, "Economic burden of motorcycle accidents in Northern Ghana," Ghana Medical Journal, vol. 45, pp. 135-142, 2011.

[15] V. Shankar and F. Mannering, "An exploratory multinomial logit analysis of single-vehicle motorcycle accident severity," Journal of Safety Research, vol. 27, no. 3, pp. 183-194, 1996.

[16] C.-W. Pai and W. Saleh, "An analysis of motorcyclist injury severity under various traffic control measures at three-legged junctions in the UK," Safety Science, vol. 45, no. 8, pp. 832-847, 2007.

[17] P. Savolainen and F. Mannering, "Probabilistic models of motorcyclists' injury severities in single- and multi-vehicle crashes," Accident Analysis \& Prevention, vol. 39, no. 5, pp. 955-963, 2007.

[18] T. Bjørnskau, T. O. Nævestad, and J. Akhtar, "Traffic safety among motorcyclists in Norway: a study of subgroups and risk factors," Accident Analysis \& Prevention, vol. 49, pp. 50-57, 2012.

[19] J. Oxley, M. D. Ravi, J. Yuen, E. Hoareau, and H. H. Hashim, "Identifying contributing factors to fatal and serious injury motorcycle collisions involving children in Malaysia," in Proceedings of the Annals of Advances in Automotive
Medicine. Association for the Advancement of Automotive Medicine. Annual Scientific Conference, vol. 57, pp. 329-336, Barrington, IL, USA, September 2013.

[20] M. S. B. Shaheed, K. Gkritza, W. Zhang, and Z. Hans, “A mixed logit analysis of two-vehicle crash severities involving a motorcycle," Accident Analysis \& Prevention, vol. 61, pp. 119-128, 2013.

[21] A. C. Mefire, J. Atashili, J. G. Tsiagadigui, C. F. Awah, and M. N. Ngowe, "A prospective pilot cohort analysis of crash characteristics and pattern of injuries in riders and pillion passengers involved in motorcycle crashes in an urban area in Cameroon: lessons for prevention," BMC Public Health, vol. 15, pp. 1-8, 2015.

[22] C. Y. H. Wu and B. P. Y. Loo, "Motorcycle safety among motorcycle taxi drivers and nonoccupational motorcyclists in developing countries: a case study of Maoming, South China," Traffic Injury Prevention, vol. 17, no. 2, pp. 170-175, 2016.

[23] C. Lam, C. W. Pai, C. C. Chuang et al., "Rider factors associated with severe injury after a light motorcycle crash: a multicentre study in an emerging economy setting," PLoS One, vol. 14, Article ID e0219132, 2019.

[24] J. Thompson, M. Baldock, and T. Lindsay, "Motorcycle crashes resulting in hospital admissions in South Australia: crash characteristics and injury patterns," Journal of Road Safety, vol. 31, no. 1, pp. 10-19, 2020.

[25] M. A. Quddus, R. B. Noland, and H. C. Chin, "An analysis of motorcycle injury and vehicle damage severity using ordered probit models," Journal of Safety Research, vol. 33, no. 4, pp. 445-462, 2002.

[26] M. M. Haque and H. C. Chin, "Right-angle crash vulnerability of motorcycles at signalized intersections: mixed logit analysis," Transportation Research Record, vol. 2194, pp. 82-90, 2010.

[27] S. R. Geedipally, P. A. Turner, and S. Patil, "Analysis of motorcycle crashes in Texas with multinomial logit model," Transportation Research Record: Journal of the Transportation Research Board, vol. 2265, no. 1, pp. 62-69, 2011.

[28] S. Islam and J. Brown, "A comparative injury severity analysis of motorcycle at-fault crashes on rural and urban roadways in Alabama," Accident Analysis \& Prevention, vol. 108, pp. 163-171, 2017.

[29] M. Waseem, A. Ahmed, and T. U. Saeed, "Factors affecting motorcyclists' injury severities: an empirical assessment using random parameters logit model with heterogeneity in means and variances," Accident Analysis \& Prevention, vol. 123, pp. 12-19, 2019.

[30] A. E. Kitali, E. Kidando, P. Alluri, T. Sando, and J. H. Salum, "Modeling severity of motorcycle crashes with Dirichlet process priors," Journal of Transportation Safety \& Security, vol. 25, pp. 1-22, 2020.

[31] C.-W. Pai, K. P. Hwang, and W. Saleh, "A mixed logit analysis of motorists' right-of-way violation in motorcycle accidents at priority T-junctions," Accident Analysis \& Prevention, vol. 41, no. 3, pp. 565-573, 2009.

[32] S. Harnen, S. V. Wong, R. S. R. Umar, and W. I. W. Hashim, "Motorcycle crash prediction model for non-signalized intersections," IATSS Research, vol. 27, no. 2, pp. 58-65, 2003.

[33] L. Budd, T. Allen, and S. Newstead, "Current trends in motorcycle-related crash and injury risk in Australia by motorcycle type and attributes," Report No:336, Monash University, Melbourne, Australia, 2018.

[34] C. Ding, M. Rizzi, J. Strandroth, U. Sander, and N. Lubbe, "Motorcyclist injury risk as a function of real-life crash speed and other contributing factors," Accident Analysis \& Prevention, vol. 123, pp. 374-386, 2019. 
[35] K. S. Oluwadiya, O. D. Ojo, O. O. Adegbehingbe, C. Mock, and O. S. Popoola, "Vulnerability of motorcycle riders and coriders to injuries in multi-occupant crashes," International Journal of Injury Control and Safety Promotion, vol. 23, no. 2, pp. 189-196, 2016.

[36] A. Rosenberg, F. Z. Uwinshuti, M. Dworkin et al., "The epidemiology and prehospital care of motorcycle crashes in a sub-Saharan African urban center," Traffic Injury Prevention, vol. 21, no. 7, pp. 488-493, 2020.

[37] J. Bello, A. Nasir, B. Solagberu, C. Ofoegbu, and L. AbdurRahman, "Motorcycle transport: a threat to road safety in a community in Sub-Saharan Africa," Injury Prevention, vol. 18, p. A191, 2012.

[38] A. A. Sanusi and M. Emmelin, "Commercial motorcycle drivers' perceptions of risk and road safety in urban Nigeria: an explorative study," International Journal of Injury Control and Safety Promotion, vol. 22, no. 4, pp. 328-339, 2015.

[39] K. Zimmerman, D. Jinadasa, B. Maegga, and A. Guerrero, "Road traffic injury on rural roads in Tanzania: measuring the effectiveness of a road safety program," Traffic Injury Prevention, vol. 16, no. 5, pp. 456-460, 2015.

[40] L. Diaz Olvera, D. Plat, and P. Pochet, "Looking for the obvious: motorcycle taxi services in Sub-Saharan African cities," Journal of Transport Geography, vol. 88, Article ID 102476, 2020.

[41] P. Starkey, "The benefits and challenges of increasing motorcycle use for rural access," in Proceedings of the International Conference on Transportation and Road Research, pp. 1-17, Mombasa, Kenya, March 2016.

[42] S. A. Sumner, A. J. Pallangyo, E. A. Reddy et al., "Effect of free distribution of safety equipment on usage among motorcycletaxi drivers in Tanzania-A cluster randomised controlled trial," Injury, vol. 45, no. 11, pp. 1681-1686, 2014.

[43] L. Diaz Olvera, A. Guézéré, D. Plat, and P. Pochet, "Earning a living, but at what price? Being a motorcycle taxi driver in a Sub-Saharan African city," Journal of Transport Geography, vol. 55, pp. 165-174, 2016.

[44] P. T. Savolainen, F. L. Mannering, D. Lord, and M. A. Quddus, "The statistical analysis of highway crash-injury severities: a review and assessment of methodological alternatives," Accident Analysis \& Prevention, vol. 43, no. 5, pp. 1666-1676, 2011.

[45] F. L. Mannering and C. R. Bhat, "Analytic methods in accident research: methodological Frontier and future directions," Analytic Methods in Accident Research, vol. 1, pp. 1-22, 2014.

[46] E. K. Adanu, W. Agyemang, R. Islam, and S. Jones, "A comprehensive analysis of factors that influence interstate highway crash severity in Alabama," Journal of Transportation Safety \& Security, pp. 1-25, 2021.

[47] L. Wahab and H. Jiang, "Severity prediction of motorcycle crashes with machine learning methods," International Journal of Crashworthiness, vol. 25, 2020.

[48] M. Rezapour, A. Mehrara Molan, and K. Ksaibati, "Analyzing injury severity of motorcycle at-fault crashes using machine learning techniques, decision tree and logistic regression models," International Journal of Transportation Science and Technology, vol. 9, 2020.

[49] L. Wahab and H. Jiang, "A comparative study on machine learning based algorithms for prediction of motorcycle crash severity," PLoS One, vol. 14, Article ID e0214966, 2019.

[50] A. Montella, R. de Oña, F. Mauriello, M. Rella Riccardi, and G. Silvestro, "A data mining approach to investigate patterns of powered two-wheeler crashes in Spain," Accident Analysis \& Prevention, vol. 134, Article ID 105251, 2020.

[51] A. T. Kashani, R. Rabieyan, and M. M. Besharati, "A data mining approach to investigate the factors influencing the crash severity of motorcycle pillion passengers," Journal of Safety Research, vol. 51, 2014.

[52] D. Tang, X. Yang, and X. Wang, "Improving the transferability of the crash prediction model using the TrAdaBoost.R2 algorithm," Accident Analysis \& Prevention, vol. 141, 2020.

[53] L.-Y. Chang and J.-T. Chien, "Analysis of driver injury severity in truck-involved accidents using a non-parametric classification tree model," Safety Science, vol. 51, 2013.

[54] L. Y. Chang and W. C. Chen, "Data mining of tree-based models to analyze freeway accident frequency," Journal of Safety Research, vol. 36, pp. 365-75, 2005.

[55] F. L. Mannering, V. Shankar, and C. R. Bhat, "Unobserved heterogeneity and the statistical analysis of highway accident data," Analytic Methods in Accident Research, vol. 11, pp. 1-16, 2016.

[56] D. McFadden, Econometric Models of Probabilistic Choice, Structural Analysis of Discrete Data with Econometric Applications, MIT Press, Cambridge, MA, USA, 1981.

[57] S. Washington, M. Karlaftis, F. Mannering, and P. Anastasopoulos, Statistical and Econometric Methods for Transportation Data Analysis, Chapman and Hall/CRC, Boca Raton, FL,USA, 2020.

[58] D. McFadden and K. Train, "Mixed MNL models for discrete response," Journal of Applied Econometrics, vol. 15, pp. 2-1, 2000.

[59] E. Kenneth, Train, Discrete Choice Methods with Simulation, Cambridge University Press, Cambridge, England, 2nd edition, 2009.

[60] C. R. Bhat, "Simulation estimation of mixed discrete choice models using randomized and scrambled Halton sequences," Transportation Research Part B: Methodological, vol. 37, no. 9, pp. 837-855, 2003.

[61] S. Islam, S. L. Jones, and D. Dye, "Comprehensive analysis of single- and multi-vehicle large truck at-fault crashes on rural and urban roadways in Alabama," Accident Analysis \& Prevention, vol. 67, pp. 148-158, 2014.

[62] V. Kasantikul, J. V. Ouellet, T. Smith, J. Sirathranont, and V. Panichabhongse, "The role of alcohol in Thailand motorcycle crashes," Accident Analysis \& Prevention, vol. 37, no. 2, pp. 357-366, 2005.

[63] S. M. Rifaat, R. Tay, and A. de Barros, "Severity of motorcycle crashes in Calgary," Accident Analysis \& Prevention, vol. 49, pp. 44-49, 2012.

[64] P. Wells and M. J. Beynon, "Corruption, automobility cultures, and road traffic deaths: the perfect storm in rapidly motorizing countries?" Environment \& Planning A: Economy and Space, vol. 43, no. 10, pp. 2492-2503, 2011.

[65] M. Salifu and W. Ackaah, "Under-reporting of road traffic crash data in Ghana," International Journal of Injury Control and Safety Promotion, vol. 19, pp. 331-9, 2012. 